\title{
A guerra na Grécia Antiga: aspectos técnicos e sociais
}

\author{
The war in the Ancient Greece: technical and social aspects
}

SEARS, M. A. Understanding Greek warfare. London: Routledge, 2019. 235 p.

\section{Martinho Guilherme Fonseca Soares*}

Recebido em: 10/12/2020

Aprovado em: 05/01/2021

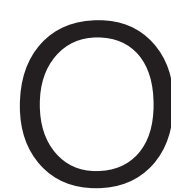

desenvolvimento de equipamentos, táticas, estratégias de combate, bem como a seleção e treinamento de soldados e combatentes são atividades relacionadas diretamente com a guerra, caracterizando o campo de pesquisa que, comumente, chamamos de História Militar. Batalhas, conflitos e os agentes que os promovem permitem ao historiador examinar a fundo a dinâmica política, social e cultural de determinado período da história, haja visto que esses conflitos são tão antigos quanto a própria experiência humana, abrindo, deste modo, um horizonte alvissareiro de possibilidades de investigação.

Nesta breve introdução ao tema, atentaremos para um caso específico sobre o qual não tardaremos a voltar: o dos gregos antigos e sua experiência belicista no Período Clássico. Tal como observa Ludmilla Marinovic (1988, p. 282), ao se referir ao papel desempenhado pelos soldados no mundo grego, é possível dizer que eles e suas táticas de combate influenciavam todos os aspectos da vida grega antiga: econômica, política, militar e ideológica, talvez porque, como assinala Matthew Trundle (2004, p. 1), a guerra clássica grega não era um acontecimento privado, mas a expressão pública da vida de um cidadão. Conforme o mesmo autor, as assembleias de cidadãos eram compostas pelas mesmas pessoas que lutavam nos exércitos das póleis, de modo que a guerra era, também ela, uma obrigação participativa e social da comunidade.

Se, de um ponto de vista ideal, o cidadão grego era, por exigência soberana, um soldado - condição para a qual se requeria a posse de propriedade fundiária —,

\footnotetext{
* Mestre pelo Programa de Pós-Graduação em História da Universidade Federal do Espírito Santo.
} 
os mercenários, por exemplo, desafiaram esse ideal. Na sociedade grega clássica, os mercenários eram prolíficos (TRUNDLE, 2004, p. 1). A guerra e tudo aquilo que lhe era correlata foi, sob este ponto de vista, produto e, ao mesmo tempo, produtora de uma série de arranjos sociais, políticos e culturais - muitas vezes conflitantes - que extrapolavam e muito seu aspecto originalmente militar. É sob este olhar que Matthew A. Sears, professor associado de História Antiga da University of New Brunswick, publicou Understanding Greek warfare (2019), obra sobre a qual nos debruçamos nesta resenha.

O livro se encontra dividido em sete capítulos, a saber: "Bronze Age and Homeric warfare: Achilles vs. Hector?"; "The hoplite phalanx: the rise of the polis"; "Greek naval warfare: ruling the Aegean"; "The fourth century BCE: mercenaries and scoundrels"; "Philip and Alexander of Macedon: crushing the polis, conquering the world"; e "Warfare in the Hellenistic world: the coming of Rome". Ao longo desses capítulos, no lugar de oferecer uma fastidiosa periodização da história militar grega e seus eventos, como parece ter se tornado o costume, o autor apresenta as principais tendências e questões sobre um período específico, incluindo as fontes antigas e a natureza das evidências desde o Período Micênico à Época Helenística.

Na Introdução de seu livro, Sears $(2019$, p. 2) recorda que o épico que marca o início da literatura grega - a llíada, de Homero - começa com uma única palavra evocativa: ira (mēnis, em grego), de modo que a llíada e, em menor medida, a Odisseia - poema cuja autoria é igualmente atribuída a Homero - , falam de grandes guerreiros em batalha que se destacam de seus oponentes lutando até a morte. Nesse sentido, para o autor, embora supostamente versem sobre o final da Idade do Bronze, os poemas homéricos, em função de sua disseminação por toda a Hélade, passaram a ser explorados como fontes de instrução moral no curso da história grega, de maneira que a temática militar que integra seu enredo passa a compor todos os demais aspectos da vida social.

No primeiro capítulo, "Bronze Age and Homeric warfare: Achilles vs. Hector?", ao realizar uma acurada análise da iconografia das cidadelas micênicas, bem como daquilo que a Arqueologia Clássica hoje nos revela, Sears demonstra que os muros das cidades micênicas foram construídos de maneira calculada: suas paredes eram mais altas e mais grossas do que o exigido por estruturas puramente táticas. Além de fornecer proteção contra os inimigos, os muros micênicos foram utilizados como recurso simbólico, na medida em que serviram como instrumento para a demonstração do poder e riqueza de seus governantes. Uma mensagem que, na avaliação do autor, era dirigida aos rivais, mas também à população que vivia por detrás das muralhas. Ao analisar algumas das tabuinhas de Linear B encontradas em Pilos, Sears demonstra que a conhecida capacidade micênica de estabelecer contato - geralmente por intermédio de entrepostos comerciais - com 
outros povos, efetivou-se também no nível militar, uma vez que os micênicos parecem ter contratado seus próprios soldados profissionais estrangeiros.

No capítulo dois da obra, "The hoplite phalanx: the rise of the polis", o autor dedicase ao estudo da falange hoplítica no contexto de ascensão da pólis. Conforme sugerido nos primeiros parágrafos, Sears $(2019$, p. 31) defende que essa formação específica dos guerreiros gregos foi importante muito além do campo de batalha, sendo consenso entre aqueles que se dedicam ao estudo do tema o entendimento de que a própria pólis, junto com seus valores - concomitantes - de igualdade e participação política foi o resultado natural e inevitável da falange. Apontando os vários debates em torno das falanges arcaica e clássica, notoriamente acerca de seu adensamento, Sears (2019, p. 45) defende que nosso olhar seja direcionado para os aspectos sociais, de maneira que, para entender como uma formação tática pode ter sido tão influente social e politicamente, precisamos investigar quem eram os soldados hoplitas, o que esteve associado a sua condição de homens livres defendendo seu próprio território no lugar de se apresentarem como tropas profissionais ou conscritas que lutavam por um rei ou pelos interesses de uma pequena elite. Ao fim do capítulo, o autor oferece um estudo de caso acerca das batalhas hoplíticas nas Termópilas e junto ao Rio Nemea.

Evocando a relação de proximidade dos gregos com o espaço marítimo, Sears recorda a célebre expressão platônica de que os habitantes da Hélade se encontravam ao redor do mar, assim como formigas e rãs em torno de um lago. Desse modo, defende que o mar era uma parte integrante da vida grega e da compreensão grega de mundo, de maneira que, em sua avaliação, o mito da Guerra de Troia demonstra que os gregos desde a Época Arcaica tinham consciência de que a navegação marítima, incluindo as expedições militares, sempre fizera parte de sua história (SEARS, 2019, p. 60). É esse o tema do terceiro capítulo, "Greek naval warfare: ruling the Aegean". O autor avalia que o mar, no lugar de separar, agiu como um conector entre as várias partes do Mundo Antigo, não apenas comercial e militarmente, mas também culturalmente. Assim, embora o hoplita pudesse ter dominado em terra, as batalhas navais se tornaram um componente essencial da estratégia de combate helena no final do Período Arcaico e, de muitas maneiras, dominaram a guerra clássica, especialmente em termos do número de homens envolvidos e da escala das batalhas que travavam (SEARS, 2019, p. 60).

Como não poderia deixar de ser, o autor apresenta um estudo detalhado dos navios de guerra grego, atendo-se, em particular, às trirremes que, segundo defende, mais do que tudo, eram feitas para o combate e que permitiram aos gregos da Época Clássica desenvolver sua talassocracia, ou seja, o "governo do mar". Mas aqui cumpre destacar uma importante observação feita por Sears $(2019$, p. 68) ao considerar os limites 
impostos pela geografia da Grécia antiga que, repleta de grandes cadeias de montanhas, repartiu-se em centenas de póleis independentes, em vez de um Estado-nação étnico ou um império. Para o autor, o domínio do mar, aperfeiçoado que foi pelos combates nele travados, eliminou muitas das restrições da geografia e permitiu que os atenienses subjugassem muitos outros gregos por exemplo. Ao fim do capítulo é apresentado um estudo de caso acerca das batalhas de Salamina e Naupactus.

No quarto capítulo, "Total war: Athens vs. Sparta", Sears, não sem razão, trata de um conflito específico: a Guerra do Peloponeso, que, de 431 a 404 a.C., envolveu muito mais do que questões militares, promovendo discussões acerca da melhor constituição, o espaço e a esfera de atuação dos soldados, cidadãos e não cidadãos. No curso do capítulo, o autor oferece uma visão detalhada das narrativas sobre a guerra, notadamente a versão dada por Tucídides, dissertando também sobre as estratégias e táticas além da falange. $O$ destaque do capítulo é o que o autor nomeia como uma new breed of leader. Figuras que, a partir da Guerra do Peloponeso, emergem no mundo grego como verdadeiros líderes, caso de Péricles, Alcibíades, Brásidas e Lisandro e outros mais que, conforme Sears (2019, p. 112), ganharam destaque por meio das oportunidades oferecidas pelo conflito, que durou vinte e sete anos. Essas quatro figuras por ele analisadas exemplificam o tipo de poder e prestígio que tais líderes militares ambiciosos e habilidosos passaram a exercer na sociedade a partir das oportunidades geradas pela guerra.

"The fourth century BCE: mercenaries and scoundrels" é o quinto capítulo do livro, dedicado à análise do século que, iniciado com uma disposição de póleis independentes e em pleno andamento, termina com o mundo mediterrâneo dividido entre reinos, todos sucessores de Alexandre, o Grande. Para Sears, o século IV a.C., no qual a guerra grega continuou a se desenvolver e mudar até culminar na máquina de guerra macedônia, merece consideração por si só. $O$ destaque do capítulo é a atuação dos mercenários e, no campo das táticas militares, a guerra de cerco. Segundo Sears (2019, p. 127), a estratégia do cerco tornou-se domínio de profissionais, levando a uma corrida armamentista por ferramentas de ataque cada vez mais sofisticadas bem como de defesa, voltadas para a construção de muros e torres mais robustos. O autor deixa claro, contudo, que apesar desses avanços táticos, a falange hoplítica permaneceu no centro dos exércitos da pólis até o triunfo da Macedônia, em 338 a.C., de modo que o século IV a.C., na verdade, foi palco de várias das maiores batalhas hoplíticas da história grega, especialmente durante a Guerra de Corinto, na primeira década do século. Ao fim do capítulo, é apresentado um estudo de caso acerca da Batalha de Lequeu (390 a.C.) e da Batalha de Mantineia (362 a.C.).

No sexto capítulo, "Philip and Alexander of Macedon: crushing the polis, conquering the world" é oferecida ao leitor uma rara oportunidade de crítica interna e externa às fontes 
que tratam de Filipe e Alexandre e que são, segundo avalia o autor, surpreendentemente problemáticas. Ao longo do capítulo, Sears (2019, p. 150 et seq.) aborda as reformas militares de Filipe, incluindo o desenvolvimento de um novo tipo de falange e o uso pioneiro da cavalaria pesada como a principal estratégia de ataque do exército. Filipe planejou uma formação de infantaria equipada, dentre outros elementos, com a sarissa, lança com pontas de ferro com meio metro de comprimento. Empunhando esta nova lança com as duas mãos, um soldado da falange macedônia poderia manter seu inimigo bem afastado (SEARS, 2019, p. 153). No campo das estratégias políticas, o autor busca entender como Filipe aproveitou as vantagens de controlar um grande Estado territorial para criar um exército permanente profissional que acabou com os gregos no célebre episódio de Queroneia, em 338 a.C. Sears destaca ainda as diferenças entre Filipe e Alexandre, encerrando o capítulo com um estudo de caso acerca do Cerco de Tiro (332 a.C.) e da Batalha de Gaugamela (331 a.C.).

O último capítulo, "Warfare, in the Hellenistic world: the coming of Rome" é dedicado ao Período Helenístico, que, segundo avalia o autor, pouco produziu para complementar ou melhorar as brilhantes inovações de Filipe e Alexandre. Em vez disso, a guerra helenística viu o surgimento de armas exóticas, como carros de corte, elefantes e navios de guerra colossais. Além disso, o desenvolvimento mais crucial de Filipe e Alexandre, ou seja, a cavalaria pesada como a principal força de ataque do exército, caiu. A dependência excessiva da falange pesada, mesmo uma com poder de ataque tão temível quanto a falange macedônia, provou ser desastrosa para os reinos helenísticos quando eles enfrentaram as legiões romanas, muito mais versáteis (SEARS, 2019, p. 181). Conforme o autor, tal como Alexandre, seus sucessores buscaram legitimidade por meio de proezas militares, não apenas em termos de comandar a lealdade dos homens que governavam, mas também na determinação dos territórios. Neste capítulo mais breve, o autor encerra suas análises também com um estudo de caso. Em lugar de focar em batalhas individuais, analisa as carreiras de dois famosos generais helenísticos: Pirro, rei do Épiro, e Aníbal, de Cartago, que resumem os pontos fortes e fracos do modo de guerra helenístico, especialmente quando manifestado em conflito com o crescente poder de Roma.

A partir do que trouxemos, Understanding Greek warfare pode ser considerado um livro cuja inovação é o forte apelo social trazido pelo autor, saindo do costumeiro relato dos equipamentos, táticas e estratégias de combate que encontramos na literatura acerca da História Militar. Cumpre destacar, ainda, o cuidado do autor ao reportar às obras clássicas, sem, contudo, abandonar discussões atuais - muitas das quais possibilitadas pelo advento das novas tecnologias de que a Arqueologia Clássica vem se valendo nos últimos anos. 
A obra apresenta uma valiosa oportunidade aos pesquisadores que dão os primeiros passos nessa área de investigação, permitindo-lhes se apropriarem das discussões mais recentes sobre o significado da guerra no mundo grego, na medida em que vários temas são trazidos a lume, seja por períodos, táticas e equipamentos de combate, seja pela ocorrência de conflitos específicos ou mesmo os sujeitos neles envolvidos. O número extenso de páginas e as esparsas notas explicativas, no entanto, dificultam a compreensão de termos pouco usuais para o leitor. Isso, porém, não descredita o trabalho empreendido por Matthew A. Sears neste livro, que se configura como uma obra atualizada, com vasta bibliografia sobre a guerra, seus múltiplos fatores e esferas de atuação na Grécia antiga.

\section{Referências}

MARINOVIC, L. P. Le mercenariat grec au IVe siècle avant notre ère et la crise de la polis. Paris: L'Université de Besançon, 1988.

SEARS, M. A. Understanding Greek warfare. London: Routledge, 2019.

TRUNDLE, M. Greek mercenaries: from the Late Archaic Period to Alexander. New York: Routledge, 2004. 